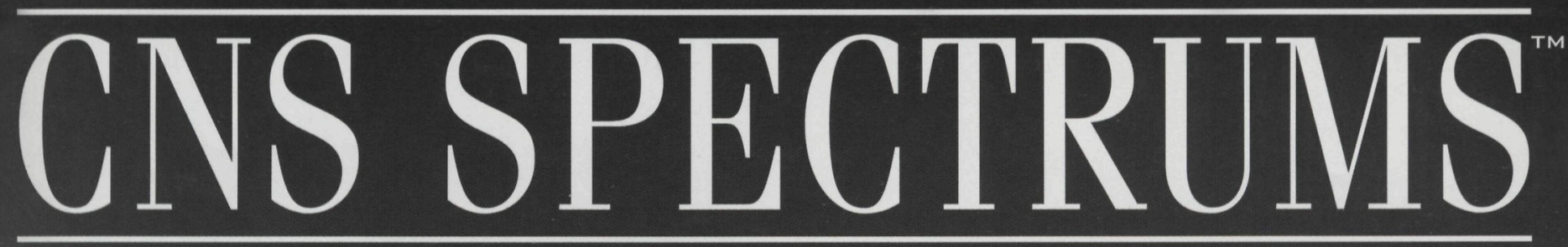

THE INTERNATIONAL JUURNAL DF NEURDPSYCHIATRIC MEDICINE
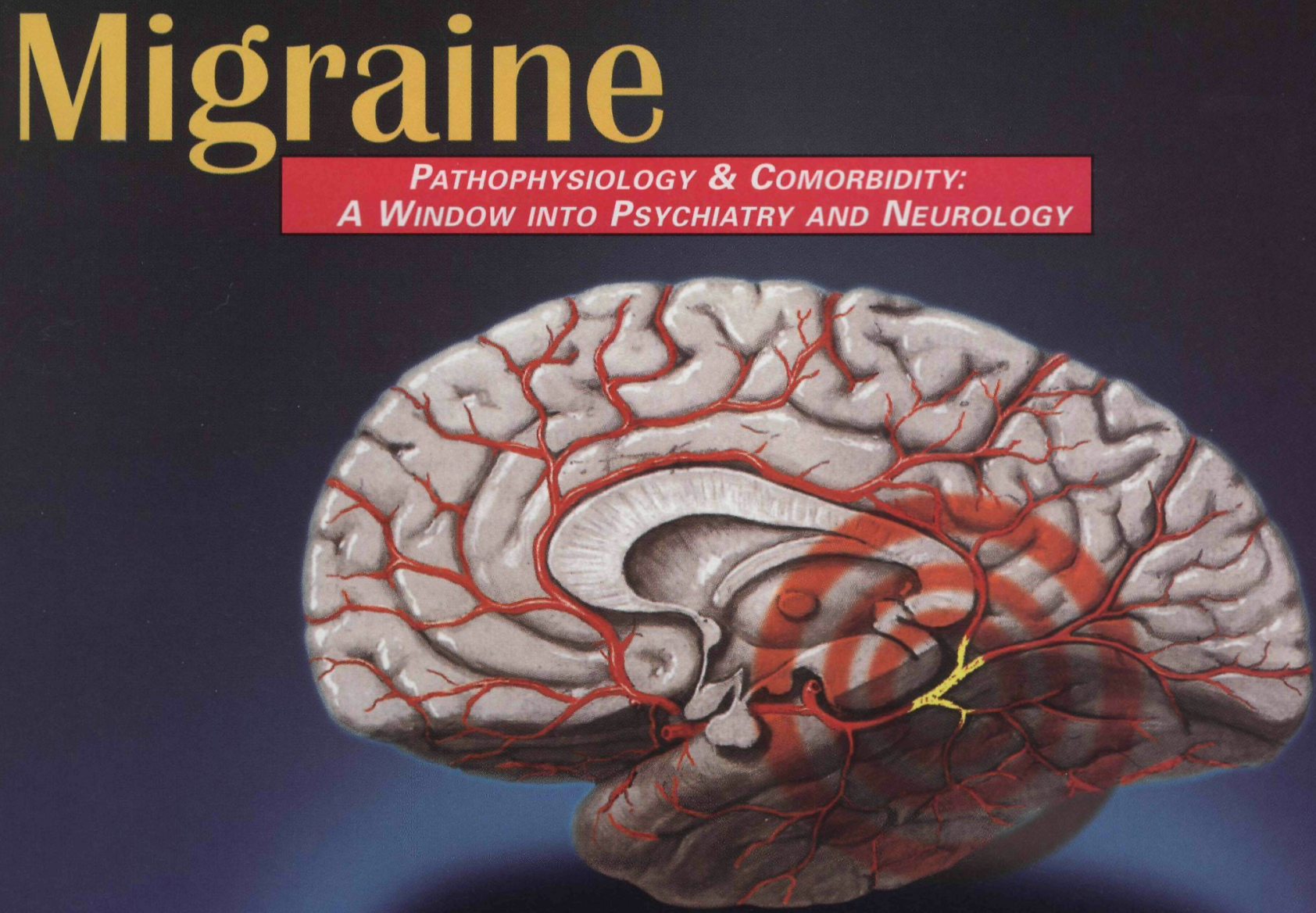

MIGRAINE: A BuRder BETWEen PSYCHIATRY AND NEUR口LugY

D. Marazkili

SERDTININ FUNCTIIN AND GENDER EFFECTS IN MIIRAINE PRDDUCTIDN AND DCD C.M. Wong, E. Hollander

CuNSENSUS STATEMENT DN THE UNDERTREATMENT QF DEPRESSIDN R.M.A. Hirscheld, M.B. Keller, et al.

CATATUNIC SYNDRDME IN AN ADDLESCENT MALE IMMIGRANT: A CASE REPURT G. P. Panikkar, D. Mayerhofi

***********************: 5-DIGIT 8P106 $\times 29521909028$ MICHAEL O FLANAGAH. MD SO? TULANE NE ALBUDUERQUE. NM BT10E-1344

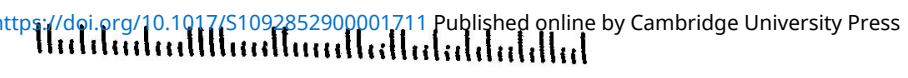

\section{PHDTD EsSAY}

The late frank Veters peerless medical illustrations have informed generations of physicians on the particulars of cerebrovascular anatomy. These drawings illustrate and describe the normal arteries and veins of the brain. showing the relationship of the many arterial and venous branches to the adiacent neuroanatomy. This computer-enhanced rendition of a Vetter drawing is being used to illustrate some of the biological causes of migraine headaches. ARTICLES INSIDE. 


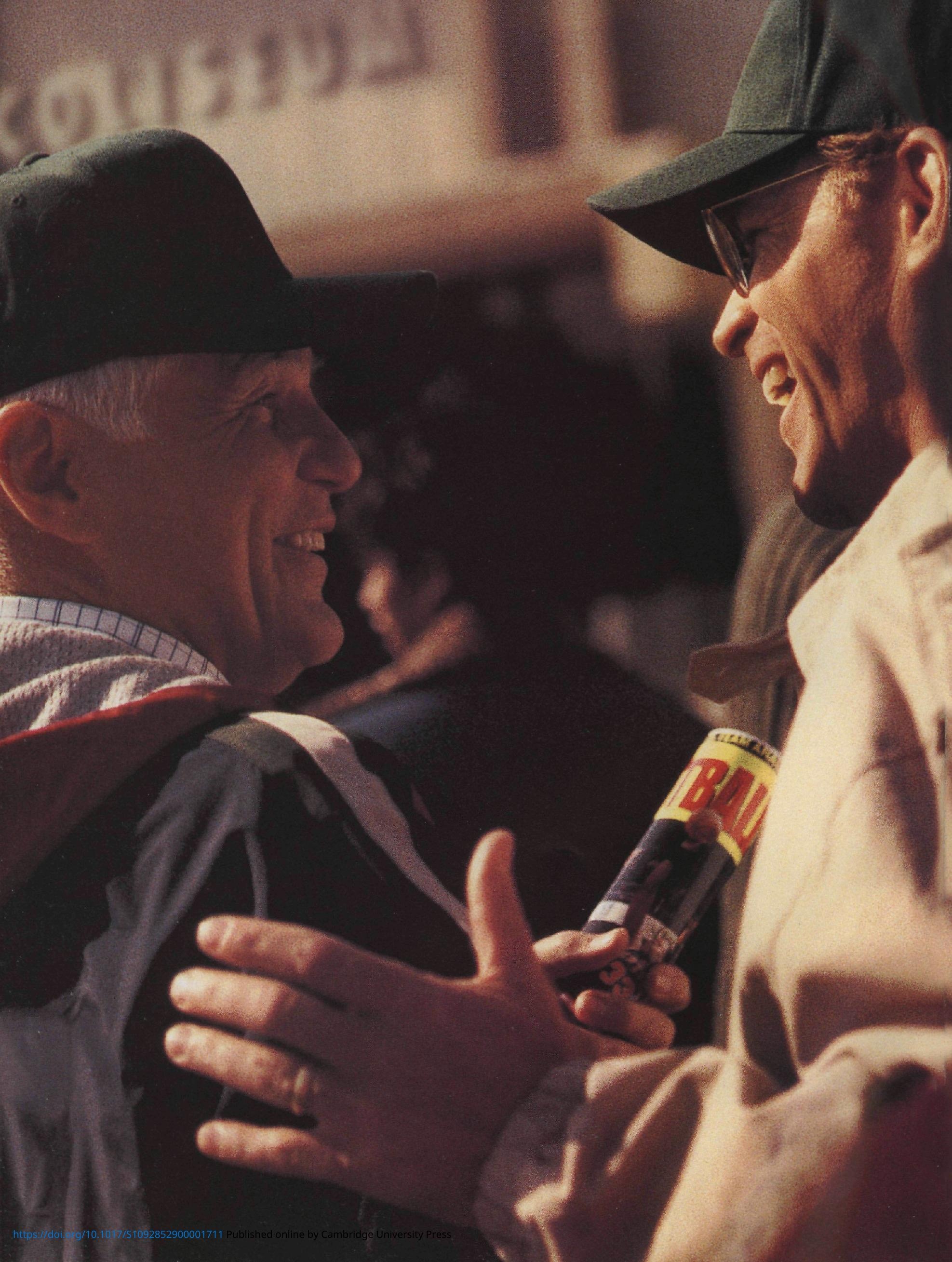




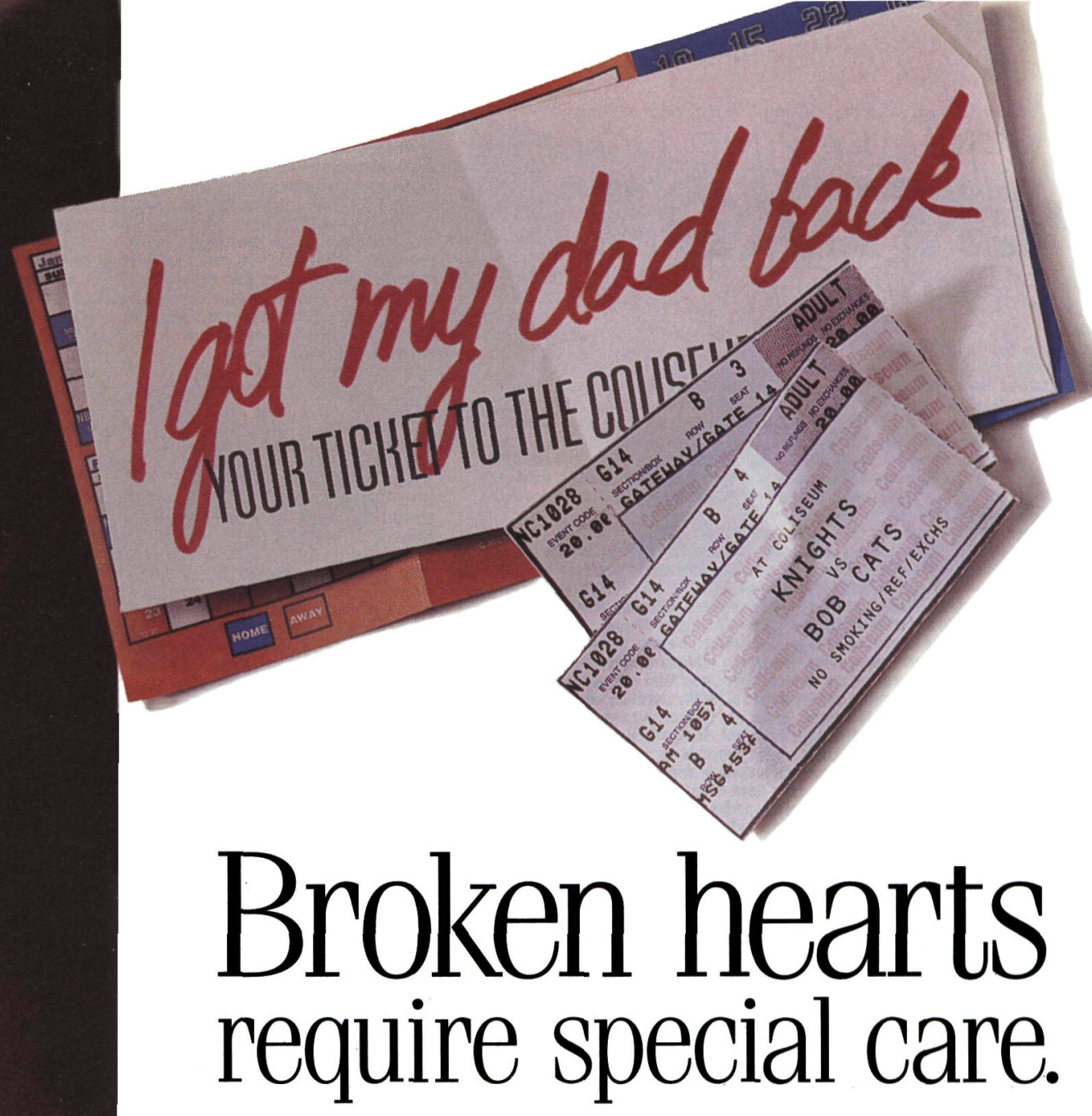

When depressed patients are also suffering from cardiovascular disease, drug-drug interaction is a critical concern. ${ }^{2.3}$ Antidepressants that compete with cardiovascular agerits utilizing the CYP2D6 and/or the CYP3A4 isoenzymes may cause potentially harmful drug interactions. ${ }^{2,3}$ EFFEXOR, while effectively treating depression, has a low potential to interact with other agents utilizing these CYP isoenzymes. ${ }^{3}$ By relieving depression, EFFEXOR can help bring patients and families together again.

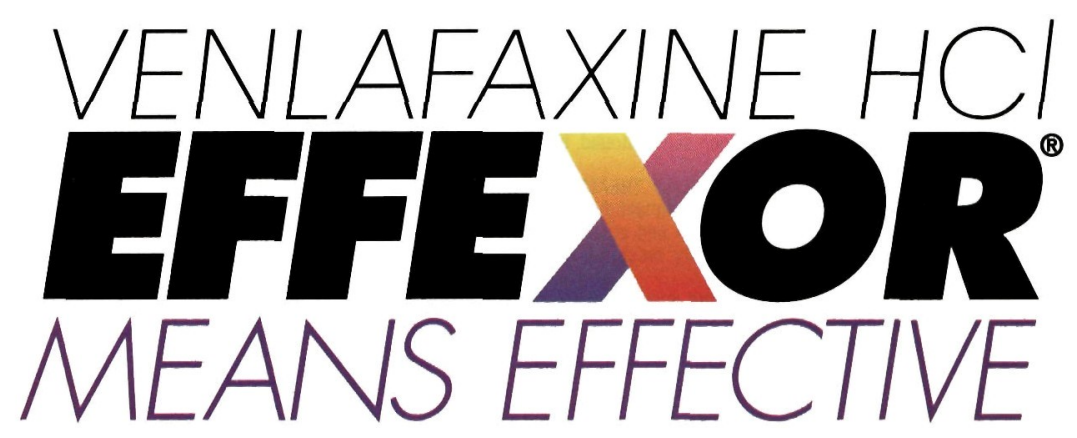

Please see brief summary of Prescribing Information accompanying this advertisement. 


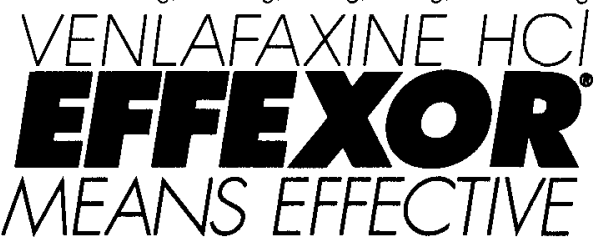

Brlef Summary

\section{(venlafaxine hydrochloride) Tablets}

\section{See package Insert for full prescrlbing informatlon.}

Clinical Pharmacology: The antidepressant action of venlafaxine is believed to be associated with potentiation of neurotransmitter activity in the CNS. In preclinical studies, venlafaxine and its active metabolite, 0-desmethylvenlafaxine (ODV), were potent inhibitors of neuronal serotonin and norepinephrine reuptake and weak inhibitors of dopamine reuptake. Venlafaxine and ODV have no significant affinity for muscarinic, histaminergic, or $\alpha-1$ adrenergic receptors in vitro. Pharmacologic activity at these receptors is hypothesized to be associated with the various anticholinergic, sedative, and cardiovascular effects seen with other psychotropic drugs. Venlafaxine and ODV do not possess monoamine oxidase (MAO) inhibitory activity.

Indications and Usaga: Effexor is indicated for the treatment of depression.

Contraindications: Contraindicated in patients with known hypersensitivity. Concomitant use in patients taking monoamine oxidase inhibitors (MAOIs) is contraindicated (see "Warnings") patients taking monoamine oxidase inhibitors (MAOIs) is contraindicated (see "Warnings").
Warnings: POTENTIAL FOR INTERACTION WITH MONOAMINE OXIDASE iNHIBITORS (MAOIs) Warnings: POTENTIAL FOR INTERACTION WITH MONOAMINE OXIDASE INHIBITORS (MAOIS)Adverse reactions, some serious, have been reported when venlafaxine therapy is initiated soon
after discontinuation of an MAOI and when an MAOI is initlated soon after discontinuation of venafter discontinuation of an MAOI and when an MAOI is inltlated soon after discontinuation of venlalaxine. Peactlons have included tremor, myoclonus, diaphoresis, nausea, vomiting, flushing
dlzziness, hyperthermla with features resembling neuroleptic malignant syndrome, seizures, and death. Given these reactions as wall as the serious, sometimes fatal inleractions reported with concomitant or immediately consecutive administration of MAOIs and other antidepressants with pharmacologlcal properties similar to Eliexor, do not use Effexor in combination with an MAOI or within at least 14 days of dlscontinuing MAOI treatment. Allow at least 7 days after stopping Ellexor before starting an MAOI. Hyperthermia, rigidity, myoclonus, autonomic instability, mental status changes including extreme agitation progressing to delirium and coma, and features resembling neuroleptic malignant syndrome have been reported with concomitant selectures resembling nouroleptic malignant syndrome have been reported with concomitant selec-
tive serotonin reuptake inhibitor/MAOl therapy. Severe hyperthermia and seizures, sometimes tive serotonin reuptake inhibitor/MAOl therapy. Severe hyperthermia and seizures,

fatal, have been reported with concomitant tricyclic antidepressants/MAOI therapy.
SUSTAINED HYPERTENSION-Effexor treatment is associated with dose-related sustained increas es in supine diastolic blood pressure. Regular monitoring of blood pressure is recommended, and when appropriate, consider dose reduction or discontinuation.

Precaullions: GENERAL - Anxiety and insomnia: Anxiety, nervousness, and insomnia have been reported in short-term studies.

Changes in Appetite/Weight: Anorexia has been reported in short-term studies, and a dose-dependent weight loss has been reported in patients taking Effexor for several weeks.

Activation of Mania/Hypomania: Hypomania or mania has been reported; as with all antidepressants. use cautiously in patients with a history of mania.

Seizures: Seizures were reported in premarketing testing $(0.26 \%)$. Use cautiously in patients with a history of seizures. Discontinue it in any patient who develops seizures.

Suicide: The possibility of suicide attempt is inherent in depression and may persist until significant remission occurs. Closely supervise high-risk patients during initial drug therapy. Write Effexor pre-
scriptions for the smallest quantity consistent with good patient management to reduce risk of overdose. scriptions tor the smallest quantity consistent with good patient management to reduce risk of overdose tant systemic illness is limited. Use cautiously in patients with diseases or conditions that could affect metabolism or hemodynamic responses. In patients with renal impairment (GFR=10 $70 \mathrm{~mL} / \mathrm{min}$ ) or liver cirrhosis, clearance of venlafaxine and its active metabolite were decreased resulting in prolonged elimination half-lives. A lower dose may be necessary; use with caution in such patients.

作 chomotor, cognitive, or complex behavior performance. However caution patients about operating hazardous machinery, including automobiles, until they are reasonably sure that Effexor does not adversely affect their ability to engage in such activities. Tell patients to 1) notify their physician if they become pregnant or intend to become pregnant during therapy, or if they are nursing; 2) inform physician about other medications they are taking or plan to take: 3) avoid alcohol while taking Effexor; 4) notify their physicians if they develop a rash, hives, or related allergic phenomena DRUG INTERACTIONS-Cimetidine: Use caution when administering Effexor with cimetidine to patients with pre-existing hypertension or hepatic dysfunction, and the elderly. Drugs Inhibiting Cytochrome $P_{450} / 1 D_{6}$ Metabolism. In vitro, venlafaxine is metabolized to its active metabolite, O-desmethylvenlafaxine (ODV), via cytochrome $P_{450} / 1 D_{6}$. Therefore drugs inhibiting this isoenzyme could potentially increase plasma concentrations of venlafaxine and decrease concentrations of 0 . Drugs Metabolized by Cytochrome $P_{450} / 1 D_{6}:$ In vitro, venlafaxine is a relatively weak inhibitor of this isoenzyme; clinical significance is unknown. Monoamine Oxidase Inhibitors. See "Contraindications"
and "Warnings." CNS-Active Drugs: Use of venlafaxine with CNS-active drugs has not been systematically evaluated; therefore, use caution when administering Effexor with such drugs.

CARCINOGENESIS, MUTAGENESIS, IMPAIRMENT OF FERTILITY-Carcinogenesis: In 18-month studies, there was no evidence of carcinogenicity in mice given $120 \mathrm{mg} / \mathrm{kg} /$ day $[16$ times the maximum recommended human dose (MRHD)]. In 24-month studies, there was no evidence of carcinogenicity in rats given $120 \mathrm{mg} / \mathrm{kg} / \mathrm{day}$. Mutagenicity: In male rats receiving 200 times (on a mg/kg Fertility: No impaired reproductive function was found in rats given 8 times $(\mathrm{mg} / \mathrm{kg})$ the MRHD.

PREGNANCY-Teratogenic Effects-Pregnancy Category $C$. Reproduction studies in rats given 11 stillborn pups, and an increase in pup deaths during the first 5 days of lactation when dosing began during pregnancy and continued until weaning. There are no adequate and well-controlled studies in pregnant women; use Effexor during pregnancy only if clearly needed.

LABOR, DELIVERY, NURSING - The effect on labor and delivery in humans is unknown. It is also not known whether Effexor or its metabolltes are excreted in human milk; exercise caution when administering to a nursing woman.

PEDIATRIC USE-Satety and effectiveness in children ( $<18$ years) have not been established. GERIATRIC USE-In clinical trials, $12 \%$ of Effexor-treated patients were $\geq 65$ years of age. Overall differences in efficacy or safety in the elderly have not been demonstrated, however, greater sensi-

tivity of older patients should not be ruled out. (537/2897) of Effexor patients in clinical trials discontinued treatment due to an adverse event. The more common events $(>1 \%)$ associated with discontinuation and considered to be drug-related included: somnolence, insomnia, dizziness, nervousness, dry mouth, anxiety, nausea, abnormal

ejaculation (male), headache, asthenia, and sweating.
INCIDENCE IN CONTROLLED TRIALS-Commonly Observed Adverse Events in Controlled Clinical Trials: The most commonly observed adverse events associated with the use of Effexor (incidence of $5 \%$ or greater and incidence for Effexor at least twice that for placebo): asthenia ( $12 \%$ vs. $6 \%$ ) sweating $(12 \%$ vs. $3 \%)$, nausea (37\% vs. $11 \%)$, constipation ( $15 \%$ vs. $7 \%)$, anorexia $(11 \%$ vs. $2 \%)$, vomiting ( $6 \%$ vs. $2 \%$ ), somnolence ( $23 \%$ vs. $9 \%$ ), dry mouth $(22 \%$ vs. $11 \%)$, dizziness $(19 \%$ vs. $2 \%)$, abnormal ejaculation/orgasm male $(12 \%$ vs. $<1 \%)$, and male impotence $(6 \%$ vs. $<1 \%)$. Adverse Events Occurring at an Incidence of $1 \%$ or More Among Effexor-Treated Patients: The fol- lowing occurred in 4- to 8- week placebo-controlled trials, with doses of 75 to $375 \mathrm{mg} /$ day, at a frequency of $1 \%$ or more. This includes patients with at least one episode of an event at some time during treatment Body as a Whole: headache, asthenia, infection, chills, chest pain, trauma Cardiovascular: vasodilatation, increased blood pressure/hypertension, tachycardia, postura hypotension. Dermatological: sweating, rash, pruritus. Gastrointestinal: nausea, constipation, anorexia, diarrhea, vomiting, dyspepsia, flatulence. Metabolic: weight loss. Nervous System: som nolence, dry mouth, dizziness, insomnia, nervousness, anxiety, tremor, abnormal dreams, hypertonia, paresthesia, libido decreased, agitation, confusion, thinking abnormal, depersonalization, depression, urinary retention, twitching. Respiration: yawn. Spechal Senses: blurred vision, taste perversion, tinnitus, mydriasis. Urogenital System: abnormal ejaculation/or

Studies indicate a dose dependency for some of the more common adverse events associated with Effexor use. There also was evidence of adaptation to some adverse events with continued Effexor therapy over a 6-week period.

Vital Sign Changes: In clinical trials, Effexor was associated with a mean increase in pulse rate of about 3 beats $/ \mathrm{min}$, and a dose-dependent increase in mean diastolic blood pressure of 0.7 to $2.5 \mathrm{mmHg}$

Laboratory Changes: During clinical trials, only serum cholesterol exhibited statistically significan differences from placebo (increases of $3 \mathrm{mg} / \mathrm{dL}$ from baseline); clinical significance is unknown.

4 beats per minute from baseline.
OTHER EVENTS OBSERVED DURING THE PREMARKETING EVALUATION OF EFFEXOR-During premarketing assessment, multiple doses of Effexor were administered to 2,181 patients, and the following adverse events were reported. Note: "frequent" = events occurring in at least 1/100 patients. "infrequent" $=1 / 100$ to $1 / 1000$ patients; "rare" = less than $1 / 1000$ patients. Events are classified within body system categories and enumerated in order of decreasing frequency using the definitions above. It is important to emphasize that although the events occurred during Effexor treatment, they were not necessarily caused by it.

Body as a Whole - Frequent. accidental injury, malaise, neck pain; Infrequent. abdomen enlarged, allergic reaction, cyst, face edema, generalized edema, hangover effect, hernia, intentional injury, moniliasis, neck rigidity, overdose, chest pain substernal, pelvic pain, photosensitivity reaction, suicide attempt; Rare: appendicitis, body odor, carcinoma, cellulitis, halitosis, ulcer, withdrawal syndrome. Cardiovascular system - Frequent: migraine; Infrequent. angina pectoris, extrasystoles, hypotension, peripheral vascular disorder (mainly cold feet and/or cold hands), syncope, thrombophlebitis; Rare: arrhythmia, first-degree atrioventricular block, bradycardia, bundle branch block, mitral valve disorder, mucocutaneous hemorrhage, sinus bradycardia, varicose vein. Digestive system - Frequent: dysphagia, eructation; Infrequent: colitis, tongue edema, esophagitis, gastritis, gastrom - Frequent. dysphagla, eructation; Ihfrequemt. coltis, tongue edema, esophagitis, gastritis, gastroenteritis, gingivitis, glossitis, rectal hemorrhage, hemorrhoids, melena, stomatitis, stomach uccer, mouth ulceration; Rare: cheilitis, cholecystitis, cholelithiasis, hematemesis, gum hemorrhage,
hepat|tis, lleitis, jaundice, oral moniliasis, intestinal obstruction, proctitis, increased salivation, soft stools, tongue discoloration, esophageal ulcer, peptic ulcer syndrome. Endocrine system - Rare: goiter, hyperthyroidism, hypothyroidism. Hemic and lymphatic system - Frequent: ecchymosis; Infrequent: anemia, leukocytosis, leukopenia, lymphadenopathy, lymphocytosis, thrombocythemia, thrombocytopenia, WBC abnormal; Rare: basophilia, cyanosis, eosinophilia, erythrocytes abnormal. Metabolic and nutritional - Frequent. peripheral edema, weight gain; Infrequent: alkaline phoshyperglycemia, hyperlipemia, hyperuricemia, hypoglycemia, hypokalemia, SGOT increased, thirst hyperglycemia, hyperlipemia, hyperuricemia, hypoglycemia, hypokalemia, SGoT increased, thirs hyper alcohol intolerance, bilirubinemia, BUN increased, gout, hemochromatosis, hyperkalemia, hyperphosphatemia, hypoglycemic reaction, hyponatremia, hypophosphatemia, hypoproteinemia, SGPT increased, uremia. Musculoskeletal system - Infrequent. arthritis, arthrosis, bone pain, bone
spurs, bursitis, joint disorder, myasthenia, tenosynovitis: Rare: osteoporosis. Nervous system spurs, bursitis, joint disorder, myasthenia, tenosynovitis; Rare: osteoporosis. Nervous system -
Frequent. emotional lability, trismus, vertigo; Infrequent apathy, ataxia, circumoral paresthesia, CNS stimulation, euphoria, hallucinations, hostility, hyperesthesia, hyperkinesia, hypertonia, hypotonia incoordination, libido increased, manic reaction, myoclonus, neuralgia, neuropathy, paranoid reaction, psychosis, psychotic depression, sleep disturbance, abnormal speech, stupor, torticollis; Rare akathisia, akinesia, alcohol abuse, aphasia, bradykinesia, cerebrovascular accident, loss of consciousness, delusions, dementia, dystonia, hypokinesia, neuritis, nystagmus, reflexes increased, seizures. Respiratory system - Frequent: bronchitis, dyspnea; Infrequent: asthma, chest congestion, epistaxis, hyperventilation, laryngismus, laryngitis, pneumonia, voice alteration; Rare: atelectasis hemoptysis, hypoxia, pleurisy, pulmonary embolus, sleep apnea, sputum increased. Skin and appendages - Infrequent acne, alopecia, brittle nails, contact dermatitis, dry skin, herpes simplex, herpes zoster, maculopapular rash, urticaria; Rare: skin atrophy, exfoliative dermatitis, fungal dermatitis, lichenoid dermatitis, hair discoloration, eczema, furunculosis, hirsutism, skin hypertrophy, leukoderma, psoriasis, pustular rash, vesiculobullous rash. Special senses - Frequent: abnorma vision, ear pain; infrequent cataract, conjunctivitis, corneal lesion, diplopia, dry eyes, exophthalmos eye pain, otitis media, parosmia, photophobia, subconjunctival hemorrhage, taste loss, visual field defect; Rare: blepharitis, chromatopsia, conjunctival edema, deafness, glaucoma, hyperacusis, keratitis, labyrinthitis, miosis, papilledema, decreased pupillary reflex, scleritis. Urogenital system Frequent anorgasmia, dysuria, hematuria, metrorrhagia ${ }^{*}$, urination impaired, vaginitis ${ }^{*}$; Infrequent albuminuria, amenorrhea ${ }^{*}$, kidney calculus, cystitis, leukorrhea, menorrhagla ${ }^{*}$, nocturia, bladder pain, breast pain, kidney pain, polyuria, prostatitis ${ }^{\star}$, pyelonephritis, pyuria, urinary incontinence
urinary urgency, uterine fibroids enlarged ${ }^{*}$, uterine hemorrhage ${ }^{\star}$, vaginal hemorrhage ${ }^{*}$, vaginal moniliasis*: Rare: abortion ${ }^{*}$, breast engorgement, breast enlargement, calcium crystalluria, female moniliasis*; Rare: abortion ${ }^{*}$, breast engorgement, breast enlargement, calcium crystalluria, female lactation ${ }^{*}$, hypomenorrhea*, menopause ${ }^{*}$, prolonged
number of male or female patients as appropriate.)

number of male or female patients as appropriate.) stance. In a retrospective survey of new events occurring during taper or following discontinuation, the following occurred at an incidence of $\geq 5 \%$, with incidence for Effexor at least twice that for placebo: asthenia, dizziness, headache, insomnia, nausea, and nervousness. Taper the dose gradually and monitor the patient. Evaluate patients carefully for history of drug abuse and observe such patients closely for signs of Effexor misuse or abuse (e.g. development of tolerance, incrementations of dose, drug-seeking behavior)

Dosage and Administration: The recommended starting dose is $75 \mathrm{mg} /$ day in 2 or 3 divided doses, taken with food. If needed, dose increments of up to $75 \mathrm{mg} /$ day should be made at intervals of $\mathrm{no}$ less than 4 days. Maximum recommended dose, for use in severely depressed patients, is $375 \mathrm{mg} /$ day, in 3 divided doses. When discontinuing Effexor after more than 1 week of therapy, the dose should be tapered to minimize the risk of discontinuation symptoms.

XIDASE INHIBITOR

At least 14 days should elapse between discontinuation of an MAOI and initiation of therapy with Effexor. In addition, at least 7 days should be allowed after stopping Effexor before starting an MAO (see "Contraindications" and "Warnings")

Please consult full prescribing information for detailed dosing instructions.

This brief summary is based on the current direction circulars, Cl 4193-3, Revised July 17, 1995, which is the same text as $\mathrm{Cl}$ 4268-4 with a revision date of July 17,1995 .

Belerences: 1 Shader Rl, von Moltke $L L$ Schmider J, et al. The clinician and drug interactions-an update J Clin Psychopharmacol. 1996;16:197-201. 2. Krishnan KRR, Steffens DC, Dofaiswamy PM. Psychotropic drug interactions. Primary PSychiatry. 1996;3:21-45. 3. Ereshefsky L. Drug interactions of antidepressants. Psychiatric Annais. 1996;26:342-350. 4. EFFEXOR (venlafaxine HCl) Prescribing Information, Wyeth-Ayerst Laboratories, Philadelphia, $\mathrm{Pa}$. 5. Ereshefsky $L$. Treating depression: potential drug-drug interactions: commentary. J Clin Psychopharmacol. 1996;16(suppl 2):50S-53S. 6. Data on file, Wyeth-Ayerst Laboratories, Philadelphia, Pa. 7. Guelfi JD, White $C$, Hackett $D$, et al. Eftectiveness of venlafaxine in patients hospitalized for major depression and melancholia. J Clin Psychiatry. 1995;56:450-458.

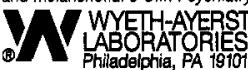

(c) 1996, Wyeth-Ayerst Laboratories

Printed in U.S.A.

$67332-01$ 


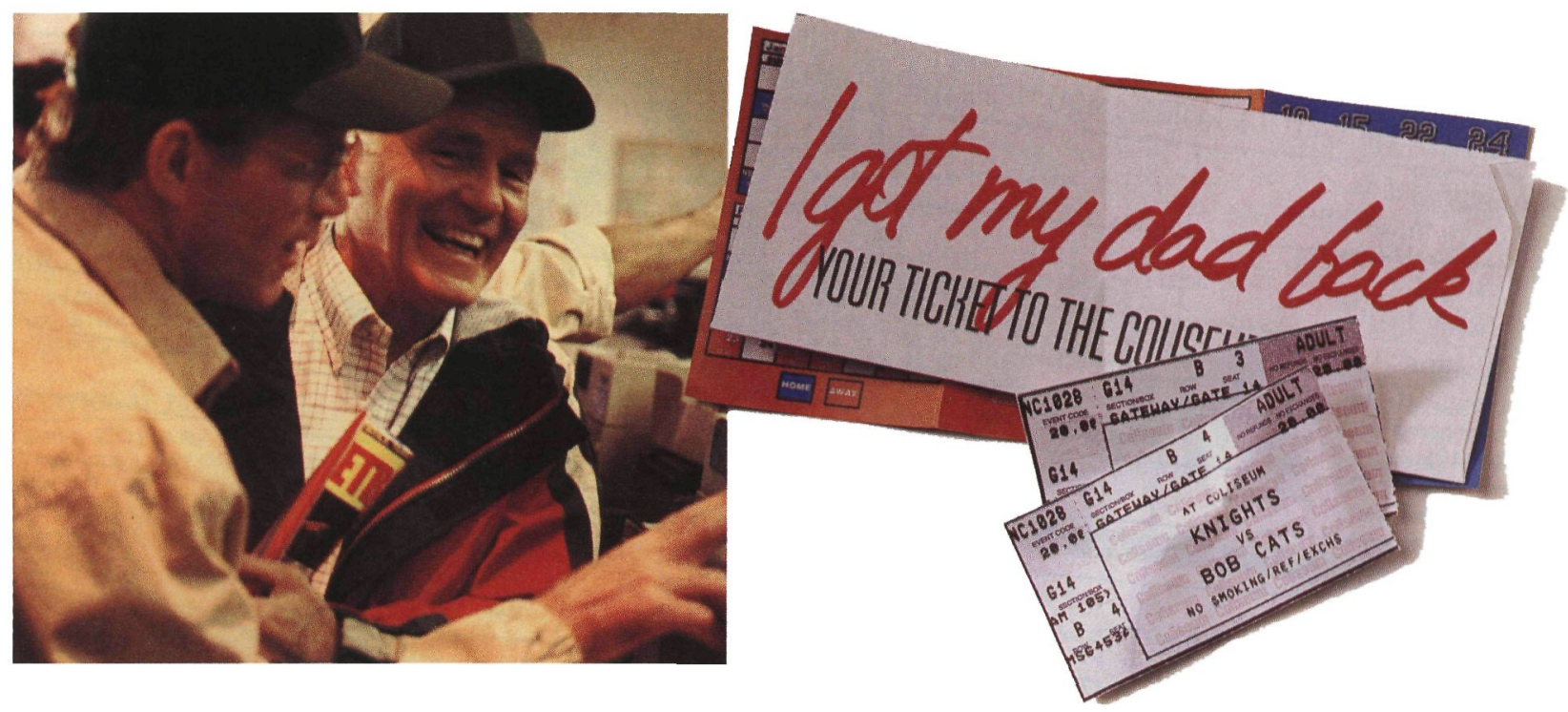

- Efficacy clearly demonstrated in depressed outpatients ${ }^{6}$

- Effective treatment in hospitalized depressed patients with major depressive disorder and melancholia meeting DSM-III-R ${ }^{\text {TM }}$ criteria $^{7}$

\section{EFFEXOR is contraindicated in patients} taking monoamine oxidase inhibitors (MAOIs). EFFEXOR should not be used in combination with an MAOI or within at least 14 days of discontinuing treatment with an MAOI because of potential for serious adverse reactions. Based on the half-life of EFFEXOR, at least 7 days should be allowed after stopping EFFEXOR before starting an MAOI.

Treatment with EFFEXOR is associated with sustained increases in blood pressure (BP) in some patients. The incidence was seen at $>5 \%$ at dosages above $200 \mathrm{mg} /$ day and appears to be dose dependent. It is recommended that patients have regular BP monitoring. For patients experiencing a sustained increase in BP, dose reduction or treatment discontinuation should be considered.

Low potential exists for interaction in patients taking lithium, diazepam, or cimetidine. ${ }^{4}$

-In combination with cimetidine, EFFEXOR should be used with caution in patients with preexisting hypertension, or in elderly patients, or in patients with hepatic dysfunction, as the

Tablets: $25 \mathrm{mg}, 37.5 \mathrm{mg}, 50 \mathrm{mg}, 75 \mathrm{mg}$, and $100 \mathrm{mg}$

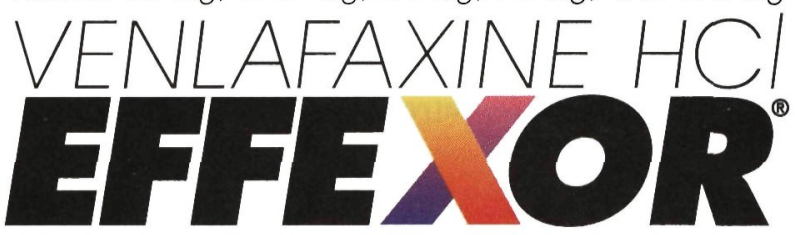

interaction between the two drugs in these patients is not known and could be more pronounced."

EFFEXOR at steady state increased the AUC of a single dose of haloperidol by $70 \%$. The mechanism explaining this finding is unknown.

EFFEXOR is a relatively weak inhibitor of cytochrome P450 2D6. ${ }^{4}$

—Weak inhibition of cytochrome P450 2D6 is an important characteristic when considering other drugs metabolized by this enzyme. ${ }^{4}$

-Potential exists for a drug interaction between EFFEXOR and drugs that inhibit cytochrome P450 2D6 metabolism. ${ }^{4}$

The most common adverse events reported in EFFEXOR clinical trials (incidence $>10 \%$ and $\geq 2 \times$ that of placebo) were nausea, somnolence, dry mouth, dizziness, constipation, nervousness, sweating, asthenia, abnormal ejaculation/orgasm, and anorexia.

EFFEXOR has not demonstrated any clinically significant impairment of psychomotor, cognitive, or complex behavior performance in healthy volunteers. However, as with any psychotropic drug, EFFEXOR may impair judgment, thinking, or motor skills; patients should be advised to exercise caution until they have adapted to therapy.

Please see brief summary of Prescribing Information on previous page of this advertisement. 


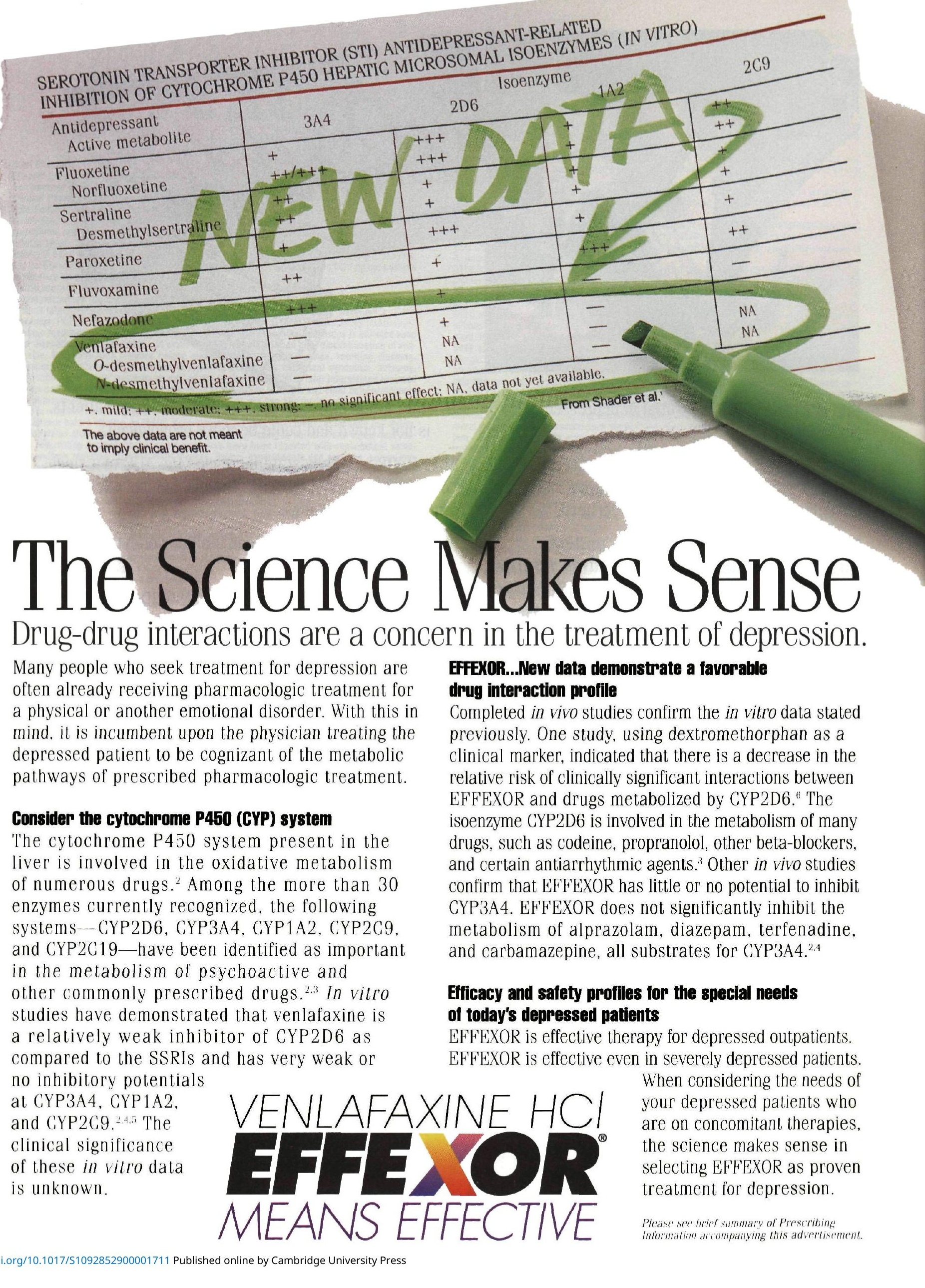


THE INTERNATIONAL JUURNAL GF NEURGPgYchiatric MEDICINE

\section{EDITOR}

ERIC HLllander, MD

MIUNT SinAI SEHOLL OF MEdICINE

NEW YORK, NY

\section{INTERNATIONAL EDITOR}

JロGEPH ZRHAR, MD

Chaim Sheba Medical Center

TEL AVIV, ISRAEL

\section{EDITORIAL DIRECTOR}

JAMES LA ROSSA JR.

\section{BOARD OF ADVISORS}

\section{SCOTT ATLAS, MD}

MIUNT SINAI SCHOOL OF MEDICINE NEW YQRK, NY

Mitchell F. BRIN, MD

MUUNT SINAI SCHOLL OF MEDICINE

NEW YQRK, NY

\section{JUHN CARONNA, MD}

THE NEW YORK HÓSPITAL-CaRNELL

MEDICAL CENTER

NEW YQRK, NY

DENNIS S. CHARNEY, MD

YALE UNIVERSITY

New HaVEN, CT

EMIL F. CRCLARD, MD

MCP AT EPPI

Philadelphia, PA

JEFFREY L. CUMMINGS, MD

UCLA DEPARTMENT QF NELRLLGGY

LOS ANGELES, CA

MARK GeqRGE, MD

MEDICAL UNIVERSITY OF SOUTH CARDLINA

ChaRLESTON, SC

JACK GRRMAN, MD

COLLEGE DF PHYSICIANS AND

SURGEONS, CLLUMBIA UNIVERSITY

NEW YORK, NY

STEVEN HYMAN, MD

National Institute of Mental Health

BETHESDA, MD

THIMAg R. INSEL, MD

YERKES PRIMATE LABS

EMORY UNIVERSITY SCHOLL OF MEDICINE

ATLANTA, GA

MICHAEl A. JENIKE, MD

MAssachusetts GENERAL Hospital

CHARLESTOWN, MA

LURRIN M. KRRAN, MD

STANFQRD UNIVERSITY MEDICAL SCHOLL

STANFIRD, CA

JAMES LECKMAN, MD

YALE UNIVERSITY

New haven, cT.
V. MARKKU LINNOILA, MD, PHD

NATIONAL INSTITUTE ON ALCOHOL ABUSE AND

ALCOHOLISM

BETHESDA, MD

Donatella Marazziti, MD

UNIVERSITY QF PISA

PISA, ITALY

Herbert Y. Meltzer, MD

VANDERBILT UNIVERSITY MEDICAL CENTER

NASHVILLE, TN

StUART A. MINTGRMERY, MD

ST. MARY'S HOSPITAL MEDICAL SCHOLL LONDON, UK

DENNIS L. MURPHY, MD

National Institute of Mental Health

BETHESDA, MD

Charles B. NemerdfF, MD

EMary UNIVERSITY SCHOLL af MEdICINE

ATLANTA, GA

HARqLD A. PINCUS, MD

AMERICAN PSYCHIATRIC AsSOCIATION

WASHINGTON, DC

STANLEY I. RAPRPRT, MD

National Institute of Mental Health

BETHESDA, MD

Alan SchatzBERG, MD

STANFIRD UNIVEESITY MEDICAL SCHOQL STANFURD, CA

NQRMAN SUSSMAN, MD

NEW YURK UNIVERSITY MEDICAL SCHOLL NEW YURK, NY

Michael R. Trimble, MD

NATLIONAL HOSPITAL FIR NEUROLGGY AND NEUROSURGERY

LDNDON, UK

Herman G.M. Westenterg, MD UNIVERSITY HOSPITAL UTRECHT

UTRECHT, NETHERLANDS

RICHARD WYATT, MD

NATI INAL INSTITUTE of MENTAL HEALTH

BETHESDA, MD

STUART YUDRFSKY, MD

Baylur College of Medicine

HOUSTIN, TX

\section{CONTRIBUTORS}

DAN STEIN, MD

UNIVERSITY QF STELLENBISCH

TYGERBERG, SDUTH Africa

CHERYL WONG, MD

MUUNT SinAI SCHOLL af MEdICINE

NEW YORK, NY

VDLUME 2, NUMBER 2

CNS SPECTRUMS

IS PUBLISHED 10 TIMES

A YEAR (JANUARY,

FEBRUARY, MARCH, APRIL,

MAY, JUNE, JULY/AUGUST,

SEPTEMBER, DCTDBER, \&

NOVEMBER/DECEMBER) BY

MBL COMMUNICATIONS, INC.,

665 BRDADWAY, NEW YORK,

NY $10012-2302$.

PERIDDicAls PISTAGE RATES PENDING AT NEW YORK, NY, AND AT ADDITIONAL MAILING DFFICES.

DNE YEAR SUBSCRIPTION RATES: DOMESTIC \$9口; FOREIGN \& 145 ;

IN-TRAINING \$5口.

FOR SUBSCRIPTIONS:

$212-328-\square 800$

PISTMASTER: SEND ADDRESS CHANGES TQ CNS SPECTRUMS

665 BRDADWAY, NEW YORK, NY $10012-2302$.

FOR EDITORIAL AND ADVERTISING INQUIRIES: TELEPHDNE: $212-328-\square$ FACSIMILE:

21 2-328-口6口ᄆ

DPINIONS AND VIEWS EXPRESSED BY AUTHDRS ARE THEIR DWN AND DD NOT NECESSARILY REFLECT THE VIEWS $\square F$ THE PUBLISHER, MBL CDMMUNICATIONS, INC., QR THE EDITORIAL ADVISDRY BDARD. ADVERTISEMENTS IN CNS SPECTRUMS ARE ACCEPTED QN THE BASIS DF ADHERENCE TD ETHICAL MEDICAL STANDARDS, BUT ACCEPTANCE DOES NOT IMPLY ENDIRSEMENT BY CNS SPECTRUMS, QR THE PUBLISHER.

CNS SPECTRUMS IS A TRADEMARK OF CNS SPECTRUMS, LLC, NEW YORK, NY.

PERMISSIDN TO REPRDDUCE ARTICLES IN WHOLE DR PART MUST BE DBTAINED IN WRITING FRDM THE PUBLISHER.

CDPYRIGHT (C) 1997 BY MBL COMMUNICATIONS, INC. ALL RIGHTS RESERVED. PRINTED IN THE UNITED STATES.

Art Assistants

QUINN BATSan, ALAN IRIKURA

Photographer

Michael Wang
Copy Editors

JUHN SHIEMAKER

NITZA WILON

Associate Editor

LAUren A. Cerruto

Corporation Counsel

LEA IsELIN, Esq.

KEVIN SAYER, Esq.

LANKENAU KOUNER \& KURTZ

Of Counsel

SUSAN G. LA Rossa, Esq. LaRossa Mitchell \& Ross

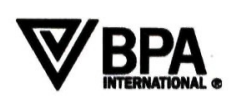

An 


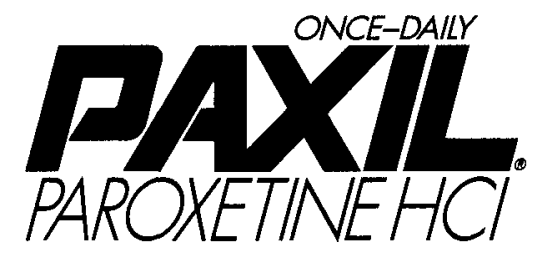

References:

1. Dunbar CC, Cohn JB, Fabre LF, et al, Br J Psychiatry, 1991;159:394-

398. 2. Cohn JB, Wilcox CS. J Clin Psychiatry. 1992;53(suppl): 52-56

3. Feighner JP, Boyer WF. J Clin Psychiatry, 1992;53(suppl):44-47.

4. Fabre LF. J Clin Psvchiatry. 1992;53(suppl):40-43. 5. Sheehan D,

Dunbar GC, Fuell DL. Psychopharmacol Bull. 1992;28:139-143.

6. Clayton PJ, Grove WM, Coryell W, et al. Am J Psychiatry. 1991:148:

1512-1517. 7. Paxil $^{\star}$ (paroxetine $\mathrm{HCl}$ ) Prescribing Information.

PAXIL' (brand of paroxetine hydrochloride)

Sas complote preacribing information in SmithKlina Beschem Pharmaceuticals literature or PDR. The lollowing is a brigi summary.

INDICATIONS AND USAGE: Paxifis indicated for the treatment of depression, obsessions and compulsions in patients with obsessive compulsive disorder (OCD) as defined in DSM IV, and panic disorder, with or without agoraphobia, as defined in DSM-IV

CoNTRANoICATIONS: Concomitant use in patients taking monoamine oxidase inhibitors (MAOls) is contraindicated. (See WARNINGS and PRECAUTIONS.)

WARNINGS: Interactions with MAOIs may occur. Given the fatal interections reported with concomltamt or immediatoly consocutive administration of MAOIs and other SSRis, do not use Pax/lin comafter stopping Paxil bolore staning a MAOI.

PRECAUf ONS: As with all antidepressants, use Paxil cautiously in patients with a history of mania.

Use Paxil cautiously in patients with a history of seizures. Discontinue it in any patient who develops seizures. The possibility of suicide attempt is inherent in depression and may persist until significant remission occurs. Close supervision of high-risk patients should accompany initial drug therapy. Write Paxil prescriptions for the smallest quantity of tablets consistent with good patient management in order to reduce the risk of overdose. Reversible hyponatremia has been reported, mainly in elderly patients, patients taking diuretics or those who were otherwise volume depleted. Abnormal bleeding (mostly ecchymosis and purpura), including a case of impaired platelet aggregation, has been reported; the relationship to paroxetine is unclear.

Clinical experience with Paxil in patients with concomitant systemic illness is limited. Use cautiously in patients with diseases or conditions that could affect metabolism or hemodynamic responses. Observe the usual cautions in cardiac patients. In patients with severe renal impairment (creatinine clearance $<30 \mathrm{~mL} / \mathrm{min}$.) or severe hepatic impairment, a lower starting dose $(10 \mathrm{mg})$ should be used.

Caution patients about operating hazardous machinery, including automobiles, until they are reasonably sure that Paxil therapy does not affect their ability to engage in such activities. Tell patients 1) to continue therapy as directed; 2) to inform physicians about other medications they are taking of plan to take; 3 ) to avoid alcohol while
taking Paxil; 4) to notify their physicians if they become pregnant or intend to become pregnant during therapy,

Concomitant use of Paxil with tryptophan is not recommended. Use cautiously with warfarin. When administering Paxil with cimetidine, dosage adjustment of Paxil after the $20 \mathrm{mg}$ starting dose should be guided by clinical effect. When co-administering Paxil with phenobarbital or phenytoin, no initial Paxil dosags adjustment is needed; base subsequent changes on clinical effect. Concomitant use of Paxil with drugs metabolized by cytochrame $P_{450} \| D_{6}$ (antidepressants such as nortriptyline, amitriptyline, imipramine, desipramine and fluoxetine; phenothiazines such as thioridazine; Type $1 C$ antiarrhythmics such as propafenone, fecainide and encainidel or with drugs that inhibit this enzyme (e.g. quinidine) may require lower doses than usually prescribed for either Paxil or the other drug: approach concomitant use cautiously. An in vivo interaction study revealed that paroxetine had no effect on terfenadine pharmacokinetics. Additional in vitro studies showed that the inhibitory effects of paroxetine on other ||$A_{4}$ substrates (astemizole, eisapride, triazolam and cyclosporin) was at least 100 times less potent than ketoconazole, a potent IIIA inhibitor. Assuming that the relationship between paroxetine's in vitro $K$ iand its lack of effect on terfenadine's in vivo clearance predicts its effect on other IIIA $\mathrm{A}_{4}$ substrates, paroxetine's inhibition of IIIA activity should have little clinical significance. Use caution when co-administering Paxil with tricyclic antidepressants (TCAs). TCA plasma concentrations may need monitoring and the TCA dose may need to be reduced. Administration of Paxil with another tightly protein-bound drug may shift plasma concentrations, resulting in adverse effects from either ofug. Concomitant use of Paxil and alcohol in depressed patients is not advised. Undertake concomitant use of Paxil and lithium or digoxin cautiously. If adverse effects are seen when co-administering Paxil with procyclidine, reduce the procyclidine dose. Elevated theophylline levels have been reported with Paxil co-administration; monitoring theophylline levels is recommended.

In 2-vear studies, a significantly greater number of male rats in the $20 \mathrm{mg} / \mathrm{kg} /$ day group developed reticulum cell sarcomas vs. animals given doses of 1 or $5 \mathrm{mg} / \mathrm{kg} /$ day. There was also a significantly increased linear trend across dose groups for the occurrence of lymphoreticular tumors in male rats. Although there was a dose-related increase in the number of tumors in mice, there was no drug-related increase in the number of mice with Rats receiving paroxetine at $15 \mathrm{mg} / \mathrm{kg} / \mathrm{day}$ ( 2.4 times the MRHD on a mg/m² basis) showed a reduced pregnancy rate.

Prognency Catagory C. Reproduction studies performed in rats and rabbits at doses up to $6 \mathrm{mg} / \mathrm{kg} / \mathrm{day} .8 .1$ (rat) and 1.9 (rabbit) times the MRHD on a $\mathrm{mg} / \mathrm{m}^{2}$ basis, have revealed no evidence of teratogenic effects or of selective toxicity to the fetus. However, rat pup deaths increased during the first 4 days of lactation when dosing occurred during the last trimester of gestation and continued throughout lactation. The cause of these deaths is not known. There are no adequate and well-controlled studies in pregnant women. Paxil should be used in pregnancy only if the potential benefit justifies the potential risk to the fetus. The effect of Paxil on labor and to a nursing woman.

Safety and effectiveness in the pediatric population have not been established.

In worldwide premarketing Paxil clinical trials, 17\% of Paxil-treated patients were $\geq 65$ years of age. Pharmacokinetic studies revealed a decreased clearance in the elderly: however, there were no overall differences in the adverse event profile between older and younger patients.

ADVERSE REACTIONS: Incidence in Controlled Trials-Commonly Observod Adverse Events in Confrollad Clinical rrials: The most commonly observed adverse events associated with the use of Paxif in the treatment of depression (incidence of $5 \%$ or greater and incidence for Paxil at least twice that for placebo): asthenia $(15 \%$ vs. $6 \%)$, sweating $(11 \%$ vs. $2 \%$ ), nausea $(26 \%$ vs. $9 \%)$, decreased appetite ( $6 \%$ vs. $2 \%)$, somnoence $(23 \%$ vs. $9 \%)$, dizziness $(13 \%$ vs. $6 \%)$, insomnia (13\% vs. $6 \%)$, tremor $(8 \%$ vs. $2 \%)$, nervousness $(5 \%$ vs $3 \%)$, ojaculatory disturbance $(13 \%$ vs. $0 \%)$ and other male genital disorders $(10 \%$ vs. $0 \%)$

The most commonly observed adverse events associated with the use of paroxetine in the treatment of obsessive compulsive disorder (incidence of $5 \%$ or greater and incidence for Paxil at least twice that of placebol were: nausea $(23 \%$ vs. $10 \%)$, dry mouth $(18 \%$ vs. $9 \%)$, decreased appetita $(9 \%$ vs. $3 \%)$, constipation $(16 \%$ vs. $6 \%)$, dizziness $(12 \%$ vs. $6 \%$, somnolence (24\% vs.
vs. $1 \%$ ) and abnormal ejaculation (23\% vs. $1 \%$ )

The most commonly observed adverse events associated with the use of paroxetine in the treatment of panic The most commonly observed adverse events associated with the use of paroxetine in the treatment of panic
disorder (incidence of $5 \%$ or greater and incidence for Paxil at least twice that for placebo) were: asthenia (14\% disorder (incidence of $5 \%$ or greater and incidence for Paxi at least twice that for placebo) were: asthenia (14\%
vs. $5 \%)$, sweating $(14 \%$ vs. $6 \%)$, decreased appetite $(7 \%$ vs. $3 \%)$, libido decreased ( $(9 \%$ vs. $1 \%$, tremor $(9 \%$ vs. vs. $5 \%)$, sweating $(14 \%$ vs. $6 \%)$, decreased appetite $(7 \%$ vs. $3 \%)$, ibido decreased $(9 \%$ vs. $1 \%)$, tremor $(9 \%$ vs.
$1 \%$ ), abnormal ejaculation $(21 \%$ vs. $1 \%)$, female genital disorders $(9 \%$ vs. $1 \%$ ) and impotence $(5 \%$ vs. $0 \%$. Twenty percent $(1,199 / 6,145)$ of $P$ axil patients in worldwide clinical trials in depression and $11.8 \%(64 / 542)$ and $9.4 \%(44 / 469)$ of Paxil patients in worldwide trials in OCD and panic disorder, respectively, discontinued treatment due to an adverse event. The most common events $(\mathbf{2} 1 \%)$ associated with discontinuation and considered to be drug related include the following: dopression-somnolence, agitation, tremor, nausea, diarrhea, dry mouth, vomiting, asthenia, abnormal ejaculation, sweating; OCD-insomnia, dizziness, constipation, nausea, The following adverse ovents occus

作 ar more vasodilation; sweating, rash; nausea, dry mouth, constipation, diarthea, decreased appetite, flatulence, orophar-
ynx disorder, dyspepsia; myopathy, myalgia, myasthenia; somnolence, dizziness. insomnia, tremor, nervousness, anxiety, paresthesia, libido decreased, drugged feeling, confusion; yawn; blurred vision, taste perversion; ejaculatory disturbance, other male genital disorders, urinary frequency, urination disorder, female ganital disorders.
The foilowing adverse events occurred at a frequency of $2 \%$ or more among $O C D$ patients on Paxil who particThe following adverse events occurred at a frequency of $2 \%$ or more among OCD patients on Paxil who participated in placebo-controlled trials of 12-weeks duration in which patients were dosed in a range of 20 to
$60 \mathrm{mg} / \mathrm{day}$ or among patients with panic disorder on Paxil who participated in placebo-controlled trials of 10 to 12 weeks duration in which patients were dosed in a range of 10 to $60 \mathrm{mg} /$ day. asthenia, abdominal pain *, chest pain**, back pain*, chills; vasodilation" ", palpitation *"; sweating, rash"*; nausea, dry mouth, constipation, diar rhea, decreased appetite, increased appetite; insomnia, somnolence, dizziness, tremor, nervousness"**, libido decreased, agitation*, anxiety*; abnormal dreams ${ }^{* *}$, concentration impaired **, depersonalization ${ }^{* *}$,
myoclonus, amnesia $a^{* *}$, rhinitis*, abnormal vision ${ }^{* *}$, taste perversion**; abnormal ejaculation, fermale genital myoclonus, amnesia**, rhinitis", abnormal vision **, taste perversion"** abnormal ejaculation, fernale genital
disorder, impotence, urinary frequency, urination impaired ${ }^{* *}$, urinary tract infection "denotes panic disorder disorder, impotence, urinary frequency, urinati

patients only. * "denotes $O C D$ patients only.
Studies show a clear dose dependency for some of the more common adverse events associated with Paxil use There was evidence of adaptation to some adverse events with continued Pexil therapy (e.g., nausea and dizziness). Significant weight loss may be an undesirable result of Paxil treatment for some patients but, on average, patients in controlled trials had minimal labout $1 \mathrm{lb}$ loss. In placebo-controlled clinical trials, Paxil-treated patients exhibited abnormal values on liver function tests no more frequently than placebo-treated patients. Other Events Observed During the Promarketing Evaluation of Paxil: During premarketing assessment in depression multiple doses of $P$ axil were administered to 6,145 patients in phase 2 and 3 studies. During premarketing clinical trials in $O C D$ and panic disorder, 542 and 469 patients, respectively, received multiple doses
of Paxil. The following adverse events were reported. Note: "frequent" $=$ events occurring in at least $1 / 100$ patients; "infrequent" $=1 / 100$ to $1 / 1000$ patients; "rare" = less than $1 / 1000$ patients. Events are classified within body system categories and enumerated in order of decreasing frequency using the above definitions. It is important to emphasize that although the events occurred during Paxil treatment, they were not necessarily caused by it

Body as a Whole: frequent: chills, malaise; infrequent: allergic reaction, carcinoma, face edema, moniliasis, neck pain; rare: abscess, adrenergic syndrome, cellulitis, neck rigidity, pelvic pain, peritonitis, shock, ulcer. Cerdiovascular System: frequent: hypertension, syncope, tachycardia: infrequent: bradycardia, conduction abnormalities, electrocardiogram abnormal, hematoma, hypotension, migraine, peripheral vascular disorder; rare: angina pectoris, arrhythmia, atrial fibrillation, bundle branch block, cerebral ischemia, cerebrovascular accident, congestive heart failure, heart block, low cardiac output, myocardial infarct, myocardial ischemia, pallor, phlebitis, pulmonary embolus, supraventricular extrasystoles, thrombophlebitis, thrombosis, varicose vein, vascular headache, ventricular extrasystoles. Digestive Systom: infrequent: bruxism, colitis, dysphagia, eructation, gastroenteritis, gingivitis, glossitis, increased salivation, liver function tests abnormal, mouth ulceration, rectal hemorrhage, ulcerative stomatitis; rare: aphthous stomatitis, bloody diarrhea, bulimia, cholelithiasis, duodenitis, enteritis, esophagitis, fecal impactions, fecal incontinence, gastritis, gum hemorrhage, hematemesis, hepatitis, ileus, intestinal obstruction, jaundice, melena, peptic ulcer, salivary gland enlargement, stomach ulcer, stomatitis, tongue discoloration, tongue edema, tooth caries, tooth malformation. Endocrine Syatem: rare: diabetes mellitus, hyperthyroidism, hypothyroidism, thyroiditis. Homic and Lymphatic Systoms: infrequent: anemia, leukopenia, lymphadenopathy, purpura; rare: abnormal enthrocytes, basophilia, eosinophilia, hypochromic anemia, iron deficiency anemia, leukocytosis, lymphedema, abnormal lymphocytes, lymphocytosis, microcytic anemia, monocytosis, normocytic anemia, thrombocythemia. Matabolic and Nutritional: frequent: edema, weight gain, weight loss; infrequent: hypergiycemia, peripheral edema, SGOT increased, SGPT increased, thirst: rare: alkaline phosphatase increased, bilirubinemia, BUN increased, creatinine phosphokinase increased, dehydration, gamma globulins increased, gout, hypercalcemia, hypercholesteremia, hyperkalemia, hyperphosphatemia, hypocalcemia, hypoglycemia, hypokalemia, hyponatremia, ketosis, lactic dehydrogenase increased. Musculoskelotel System: frequent: arthralgia; infrequent: arthritis; rare: arthrosis, bursitis, myositis, osteoporosis, generalized spasm, tenosynovitis, tetany. Norvous Syctem: frequent: amnesia, CNS stimulation abuse, ataxia, convulsion, depersonalization, dystonia, hallucinations, hostility, hyperkinesia, hypertonia, hypesthesia, incoordination, lack of emotion, manic reaction, neurosis, paralysis, paranoid reaction; rare: abnormal electroencephalogram, abnormal gait, antisocial reaction, aphasia, choreoathetosis, circumoral paresthesia, delirium, delusions, diplopia, drug dependence, dysarthria, dyskinesia, euphoria, axtrapyramidal syndrome, fasciculations, grand mal convulsion, hyperalgesia, hypokinesia, hysteria, libido increased, manic-depressive reaction, meningitis, myel itis, neuralgia, neuropathy, nystagmus, peripheral neuritis, psychosis, psychotic depression, cough increased, rhinitis; infrequent: asthma, bronchitis, dyspnea, epistaxis, hyperventilation, pneumonia, respiratory flu, sinusitis, voice alteration; rare: emphysema, hemoptysis, hiccups, lung fibrosis, pulmonary edema, sputum increased. Skin and Appendagos: frequent: pruritus; infrequent: acne, alopecia, dry skin, ecchymosis, eczema, furunculosis, urticaria; rare: angioedema, contact dermatitis, erythema nodosum, erythema multiforme, fungal dermatitis, herpes simplex, herpes zoster, hirsutism, maculopapular rash, photosensitivity, seborrhea, skin discoloration, skin hypertrophy, skin melonoma, skin ulcer, vesiculobullous rash. Special Sensea: frequent: tinnitus; infrequent: abnormality of accommodation, conjunctivitis, gar pain, eye pain, mydriasis, otitis media. taste loss, visual field defect; rare: amblyopia, anisocoris, blepharitis, cataract, conjunctival edems, corneal ulcer, deafness, exophthalmos, eye hemorrhage, glaucoma, hyperacusis, keratoconjunctivitis, night blindness, otitis externa, parosmia, photophobia, ptosis, retinal hemorrhage. Urogonital Syotom: infrequent: abortion, otitis externa, parosmia, photophobia, ptosis, retinal hemorrhage. Urogonital syetom: infrequent: abortion,
amenorrhea, breast pain, cystitis, dysmenorrhea, dysuria, hematuria, menorthagia, nocturia, polyuria, urethritis, amenorrhea, breast pain, cystitis, dysmenorrhea, dysuria, hematurla, menorthagia, nocturia, polyuria, urethrits,
urinary incontinence, urinary retention, urinary urgency, vaginitis, rare: breast atrophy, breast carcinoma, breast enlargement, breast neoplasm, epididymitis, female lactation, fibrocystic breast, kidney calculus, kidney function
abnormal, kidney pain, leukor'hea, mastitis, metrorrhagia, nephritis, oliguria, prostatic carcinoma, pyuria, urethritis, uterine spasm, urolith, vaginal hemorthage, vaginal moniliasis.

\section{Poatmarkoting Roports}

Voluntary reports of adverse events that have been received since market introduction and not listed above that may have no causal relationship with Paxil include-acute pancreatitis, elevated liver function tests ithe most severe cases were deaths due to liver necrosis, and grossly elevated transaminases associated with severe liver dysfunction), Guillain-Barré syndrome, toxic epidermal necrolysis, priapism, thrombocytopenia, syndrome of inappropriate ADH secretion, symptoms suggestive of prolactinemia and galactorrhea, neuroleptic malignant syndrome-like events; extrapyramidal symptoms which have included akathisia, bradykinesia, cogwheel rigidity, dysdrome-like events; extrapyramidal symptoms which have included akathisia, bradykinesia, cogwheel rigidity, dys-
tonia, hypertonia, oculogyric crisis (which has been associated with concomitant use of pimozide), tremor and tonia, hypertonia, oculogyric crisis (which has been associated with concomitant use of pimozide), tremor and
trismus; and serotonin syndrome, associated in some cases with concomitant use of serotonergic drugs and with trismus; and serotonin syndrome, associated in some cases with concomitant use of serotonergic drugs and with
drugs which may have impaired Paxil metabolism (symptoms have included agitation, confusion, diaphoresis, drugs which may have impaired Paxi/ metabolism (symptoms have included agitation, contusion, diaphoresis,
hallucinations, hyperreflexia, myoclonus, shivering, tachycardia and tremor). There have been spontaneous rehallucinations, hyperreflexia, myoclonus, shivering, tachycardia and tremor). There have been spontaneous re-
ports that abrupt discontinuation may lead to symptoms such as dizziness, sensory disturbences, agitation or anxports that abrupt discontinuation may lead to symptoms such as dizziness, sensory disturbances, agitation or anxlety, nausea and sweating; these events are generally self. . limiting. There has been a report of an elevated phe-
nytoin level after 4 weeks of Paxil and phenytoin co-administration, and a report of severe hypotension when nytoin level after 4 weeks of Paxil and phenytoin
Paxil was added to chronic metoprolol treatment.

Paxil was added to chronic metoprolol treatment.
DRUG ABUSE AND DEPENOENCE: Controlled Subutence Class: Paxil is not a controlled substance. DRUG ABUSE AND DEPENDENCE: Controlled Substanes Class: Paxil is not a controlled substance.
Evaluate patients carefully for history of drug abuse and observe such patients closely for signs of Paxil misuse Evaluate patients carefully for history of drug abuse and observe such patients closely for
or abuse (e.g., development of tolerance, incrementations of dose, drug-seeking behavior). BRS-PX:L11
SB SmithKline Beocham Philadelphia, PA 19101
IANSSEN 


\section{She's anxious.}

panic disorder and obsessive-

She's agitated. compulsive disorder

\section{She can't sleep.}

\section{She's depressed.}

\section{Paxil effectively relieves depression and associated symptoms of anxiety.}

$60 \%$ to $90 \%$ of depressed patients exhibit associated symptoms of anxiety such as agitation, sleep disorders,

weight loss and gastrointestinal problems ${ }^{5,6}$

Incidence of agitation with Paxil is comparable to placebo ( $2.1 \%$ vs $1.9 \%$ ); incidence of nervousness and of anxiety vs placebo is $5.2 \%$ vs $2.6 \%$ and $5.0 \%$ vs $2.9 \%$, respectively?

Most common adverse events include: nausea, somnolence, asthenia, dizziness, insomnia, sweating, ejaculatory disturbance and other male genital disorders. ${ }^{* 7}$ Concomitant use of Paxil in patients taking monoamine oxidase inhibitors (MAOIs) is contraindicated.

"Incidence of $5 \%$ or greater and incidence for Paxil at least twice that for placebo.

Please see brief summary of prescribing information on adjacent page of this advertisement
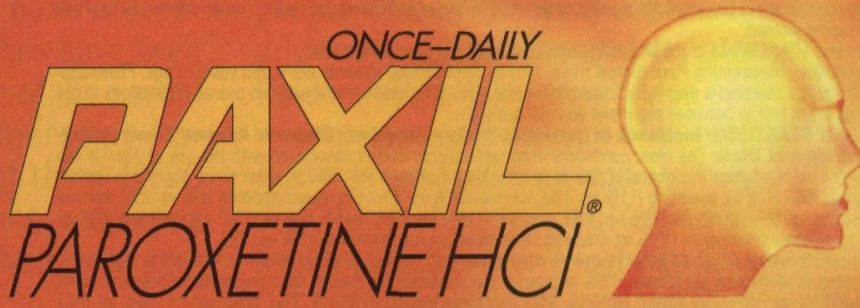

\section{LIFTS DEPRESSION.} LOWERS ASSOCIATED ANXIETY SYMPTOMS. 
on 16 Migraine: A Border Between Psychiatry and Neurology
w

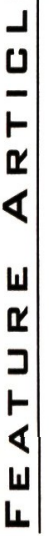
BY GRPAKUMAR P. PANIKKAR, MD, AND DAVID MAYERHQFF, MD BY RDBERT M.A. HIRSCHFELD, MD, MARTIN B. KELLER, MD, SUSAN PANICD,
24 Serotonin Function and Gender Effects in Migraine Production and OCD BY CHERYL M. WONG, MD, AND ERIC HOLLANDER, MD

33 Catatonic Syndrome in an Adolescent Male Immigrant: A Case Report

39 Consensus Statement: The National Depressive and Manic-Depressive Association Consensus Statement on the Undertreatment of Depression BERNARD 5. ARINS, MD, DAVID BARLOW, PHD, FRANK DAVIDOFF, MD, JEAN ENDICDTT, PHD, JACK FRODM, MD, MICHAEL GRLDSTEIN, MD, JACK M. GRRMAN, MD, DON GUTHRIE, PHD, RICHARD G. MAREK, MD, THEDDIR A. MAURER, RIGER MEYER, MD, KATHARINE PHILLIPS, MD, JERILYN ROSS, MA, LCSW, THOMAS L. SCHWENCK, MD, STEVEN S. SHARFSTEIN, MD, MICHAEL E. THASE, MD, AND RICHARD J. WYATT, MD $\overline{\text { CNS SPECTRUMS }}$

THE

INTERNATIINAL

JUURNAL DF

NEURDPSYCHIATRIC MEDICINE

$\mathrm{V} \mathbf{L} \cdot \mathbf{Z}-\mathrm{N} \mathbf{\mathrm { C }} \mathbf{Z}$

FEBRUARY 1997

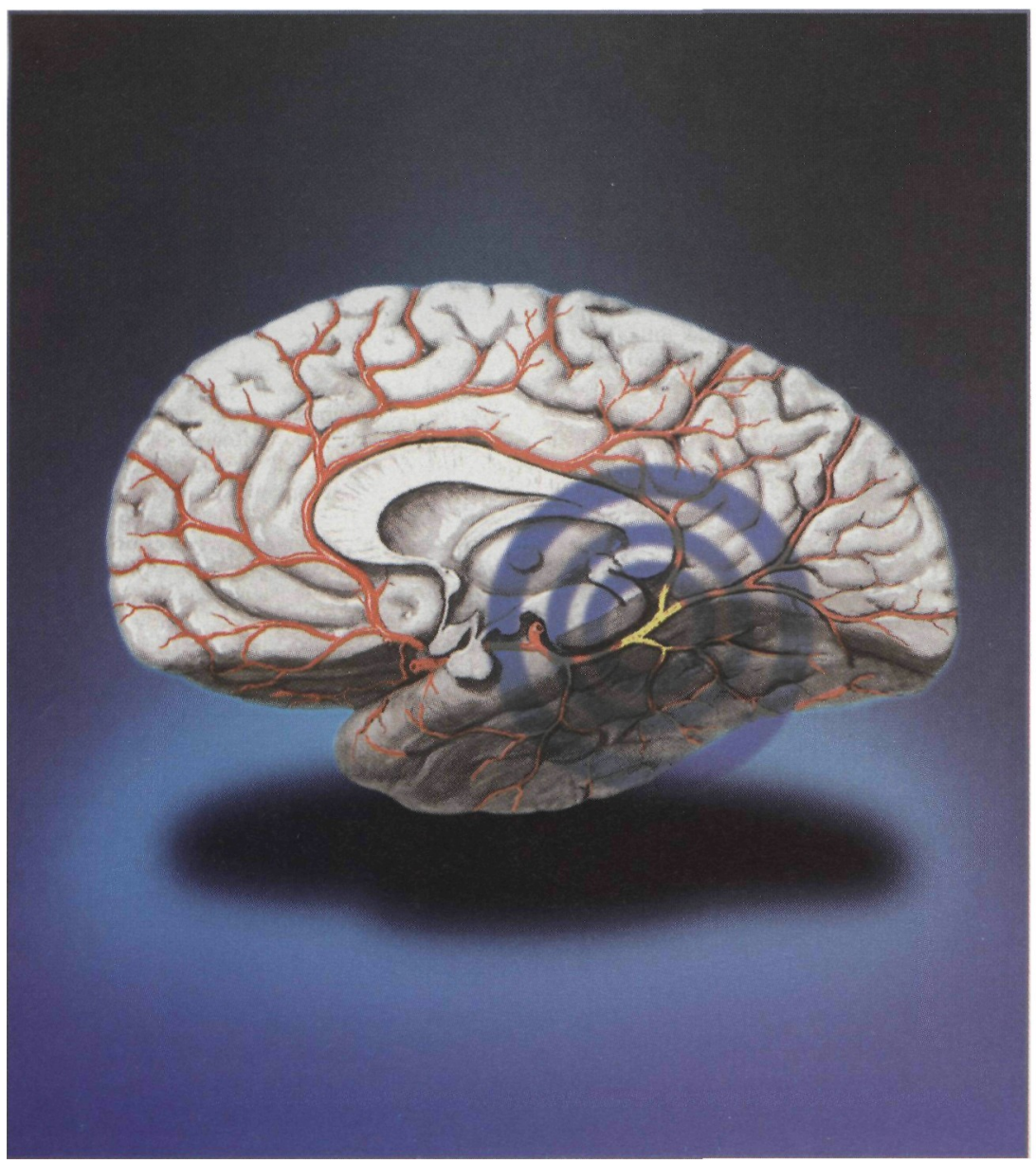

PHDTD ESSAY:

Dr. Frank Netter's peerless medical illustrations have informed generations of physicians on the particulars of cerebrovascular anatomy. For clinical practitioners of the neurosciences, knowledge of the cerebrovascular anatomy is especially helpful in evaluating patients with suspected cerebrovascular disease, infarct, intracerebral hemorrhage, vascular malformation, aneurysm, or tumor. In this issue, for example, Dr. Netter's drawings are being used to illustrate some of the biological and vascular causes of migraine headaches.

These drawings illustrate and describe the normal arteries and veins of the brain, showing the relationship of the many arterial and venous branches to the adjacent neuroanatomy. In addition, they identify the territories supplied and drained by these smaller vessels. In some patients, for whom computed tomography and angiography alone may not provide a definitive diagnosis, knowledge of the vascular anatomy involved enables the clinician to more effectively plan treatment.

Copyright 1990. Novartis. Reprinted with permission from the Clinical Symposia, Vol. 42/3, 1990, illustrated by Frank H. Netter, MD. All rights reserved. 


\section{$\overline{\text { CNS SPECTRUMS }}$}

THE

INTERNATILNAL JUURNAL OF

NEURRPGyChIATRIC MEDICINE

VaL・Z - Na・Z

FEBRUARY 1997

\section{Table of Contents}

U

\section{LETTER}

28 - Antecedents in Schizophrenics

- ABO Blood Groups, Cognition and Temperature in Alzheimer's Disease and Dementia

MIDPDINT \& CDMMENTARY

30 Migraine: Opening the Window to Psychiatry and Neurology

BY ERIC HDLLANDER, MD

AUTH口RS, GUIDELINES

321997 submission for publication guidelines.

प.

山 C $\square$ N T I N I N G

D MEDICAL EDUCATIRN

53 This continuing medical education series gives the reader the opportunity to test his/her understanding and recall of clinical material presented in this issue. Approved for 3.0 credit hours in category 2.

\section{INDICES}

56 By subject and author.
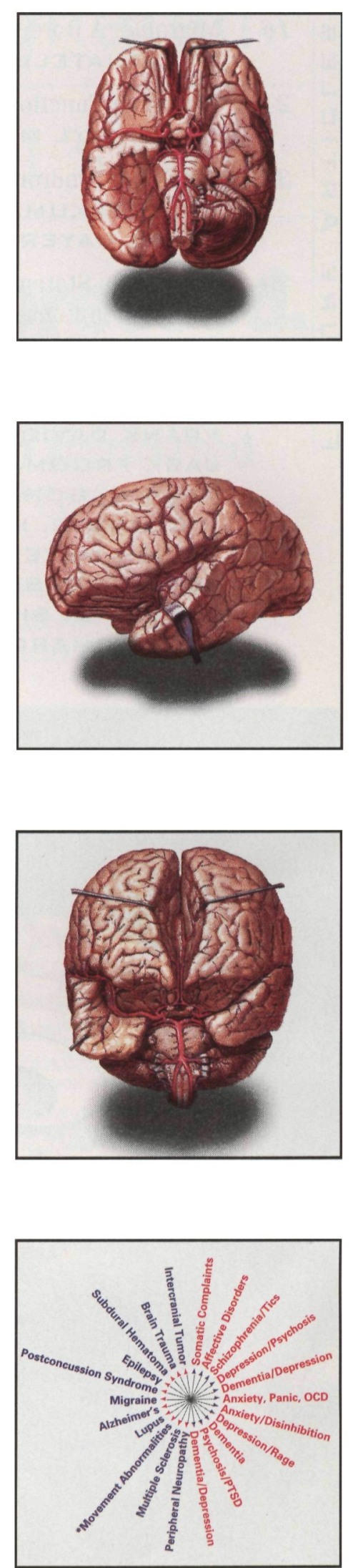


\section{For your patientes with Alzheimer's disease...}

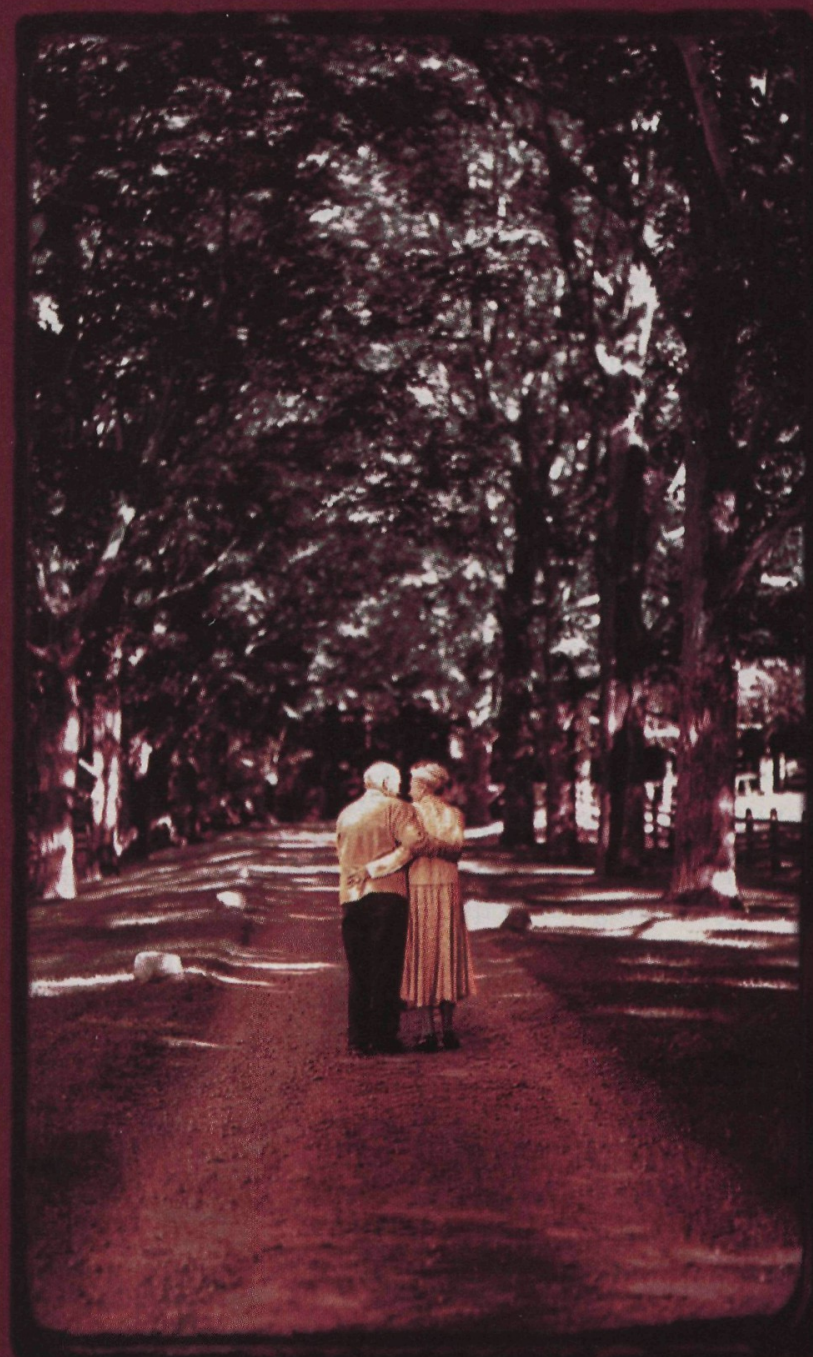

Research committed to making memory lane last a little longer...

\section{(isa) Pfizer}

A collaboration dedicated to advances in Alzheimer's therapy. 